\title{
Electroencephalographic activity during sentence production in healthy and schizophrenic men
}

\author{
Héctor J. Pelayo-González ${ }^{*}$, Dora Granados-Ramos², Víctor Alcaraz-Romero², and Verónica Reyes-Meza ${ }^{3}$ \\ ${ }^{1}$ Neuropsychology Unit, Benemérita Universidad Autónoma de Puebla, Puebla; ${ }^{2}$ Psychobiology Laboratory, Faculty of Psychology, Universidad \\ Veracruzana, Xalapa, Veracruz; ${ }^{3}$ Centro Tlaxcala de Biología de la Conducta, Universidad Autónoma de Tlaxcala, Tlaxcala, Mexico
}

\begin{abstract}
Background: Schizophrenia is a psychiatric disorder marked by hallucinations, delusions, cognitive deficit, apathy, and thinking disorders. Speech disturbance is one of the main diagnostic criteria during acute periods of schizophrenia. In addition, abnormalities of brain language areas have been consistently described in schizophrenic individuals. The aim of this study was to describe the linguistic performance and cerebral activity during sentence production using word pairs with high or low semantic relatedness. Material and methods: We recorded electrical brain activity (electroencephalography [EEG]) of 15 healthy men and 11 men with disorganized schizophrenia while they were producing sentences with high and low relatedness word pairs. Results: The results showed significant differences; participants in both groups had significant longer latencies to produce sentences with low than with high relatedness word pairs. Furthermore, sentences formed with low relatedness pairs were significantly longer than those formed with high relatedness word pairs in both groups. EEG parameters also showed differences; in healthy subjects, we found enhancement of absolute alpha rhythm over the occipital leads during the period preceding sentence production with high relatedness word pairs. Conclusion: In contrast, in schizophrenia patients producing sentences with high relatedness word pairs, it was theta and beta rhythms that were enhanced in frontal regions.
\end{abstract}

Key words: Semantic relatedness. Verbal fluency. Electroencephalography. Absolute power.

\section{Actividad electroencefalográfica durante la producción de oraciones en hombres sanos y con esquizofrenia}

\section{Resumen}

Antecedentes: La esquizofrenia es una enfermedad caracterizada por alucinaciones, déficits cognitivos, apatía y alteraciones del pensamiento. Uno de los principales criterios diagnósticos durante los periodos agudos son las alteraciones del lenguaje. El objetivo de este trabajo fue describir el desempeño lingüístico y la actividad cerebral durante la producción de oraciones usando pares de palabras con alta y baja relación semántica. Material y métodos: Registramos la actividad eléctrica (EEG) de 15 hombres sanos y 11 pacientes con esquizofrenia desorganizada mientras producian oraciones con pares de palabras con alta y baja relación semántica. Resultados: Los resultados mostraron diferencias significativas; ambos grupos

\section{Correspondence:}

*Héctor J. Pelayo-González

Neuropsychology Unit

Date of reception: 28-09-2019

Date of acceptance: $30-11-2019$

E-mail: hector.pelayo@correo.buap.mx
Available online: 02-03-2020 Rev Mex Neuroci. 2020;21(2):49-56 www.revmexneurociencia.com 1665-5044/@ 2019. Academia Mexicana de Neurología A.C. Published by Permanyer. This is an open access article under the CC BY-NC-ND license (http://creativecommons.org/licenses/by-nc-nd/4.0/). 
tuvieron latencias más largas al producir oraciones usando palabras con baja relación semántica. Además, estas oraciones fueron significativamente más largas, que aquellas formadas usando palabras con alta relación semántica, en ambos grupos. El EEG también mostró diferencias; en los sujetos sanos hubo un aumento del ritmo alfa en el occipital durante el periodo previo a la producción de oraciones con alta relación semántica. Conclusiones: En contraste, en los pacientes con esquizofrenia fueron los ritmos teta y beta los que incrementaron en regiones frontales al producir este tipo de oraciones.

Palabras clave: Cercanía semántica. Fluidez verbal. EEG. Poder absoluto.

\section{Introduction}

In patients with schizophrenia, language disorder has been considered a diagnostic indicator of the illness'. Particularly, abnormalities in connections between words and concepts are the most representative sign of thought disorder ${ }^{2-4}$.

Some studies have showed that schizophrenic patients have deficits in tasks involving semantic relations between words ${ }^{5,6}$. Building sentences with highly semantically related words lead to fast activation of their inner representation in working memory (WM) ${ }^{7}$. Sentence production involves cognitive processes that are based on the integration of activity in multiple brain regions, particularly associative cortical sites ${ }^{8,9}$.

One technique widely used to study brain mechanisms of cognitive impairments in patients with mental disorders is electroencephalography $(E E G)^{10}$. EEG studies indicate that between $50 \%$ and $60 \%$ of patients with schizophrenia show slowing of alpha rhythm, although $15 \%$ of them show beta activity between $13 \mathrm{~Hz}$ and $18 \mathrm{~Hz}$ and $10 \%$ of the patients have paroxysmal EEG changes ${ }^{11}$.

Some authors have used EEG to describe the brain functioning that underlies cognitive task performance in schizophrenic patients ${ }^{12}$. Most of the symptoms are evident while patients are solving daily life problems; cognitive researchers are aware of this problem and have developed experimental conditions that simulate life demands, such as arithmetical problem-solving ${ }^{13}$; memory retrieval ${ }^{14}$; syntactical language organization, and communication fluency ${ }^{15}$.

In this study, we analyzed the EEG during sentence production in schizophrenic and healthy men. Our objective is to identify possible changes in brain electrical activity in healthy and schizophrenic subjects during the construction of sentences using word pairs with high and low semantic relatedness. We predicted that sentence production using low relatedness word pairs requires more verbal processing and WM capacity than using high relatedness word pairs, and this would be associated to differences in EEG patterns in schizophrenic patients compared to healthy men.

\section{Methods}

The study was carried out in accordance with the Helsinki Declaration and was approved by the Faculty of Psychology Institutional Review Board at the Universidad Autónoma de Puebla (Puebla, Mexico).

\section{Participants}

We analyzed the brain electrical activity of 11 men in the acute phase of disorganized schizophrenia and 15 healthy men. Patients were recruited from the Rafael Serrano Psychiatric Hospital in Puebla, México, and healthy men were selected by advertisement. All subjects were right-handed according to the Annette scale $^{16}$. Mean age of healthy men was 32.5 years (standard deviation $[S D]=4.2)$ and 31.7 years $(S D=3.2)$ for schizophrenic subjects. Educational level of healthy men was 6.5 years $(S D=2.3)$ and schizophrenic subjects was $6.1(S D=1.4)$. Patients' mean age of schizophrenia onset was $31.3(\mathrm{SD}=0.6)$ and the mean duration of illness was 6.0 months $(S D=0.1$ ).

All of the patients had between mild and moderate illnesses according to their scores on the Scale for the Assessment of Positive Symptoms ${ }^{17}$ (mean score $=16.5$, $\mathrm{SD}=12.8$, range $=0.41$ ). Patients were evaluated 1 day after they were admitted to the hospital to avoid changes in their clinical status. All participants were native, monolingual Spanish speakers who never learned any other language. No history of head trauma, substance abuse, or addiction was recorded. After a complete description of the study, written informed consent was obtained from all participants and their relatives.

\section{Stimuli and task}

Thirty pairs of highly related words (e.g., table chair) and 30 pairs of low-related words (e.g., dog lock) were collected from the previous work ${ }^{18}$. Each participant was instructed to construct a sentence using the pair of words involved without changing the order of words or modifying the word itself (e.g., chairs instead of 
chair). We presented 33 pairs of words for each of the two conditions: low-related and high-related words.

\section{Experimental procedure}

Each subject received the instruction that after hearing the pair of words, they must construct a sentence using the pair of words without changing them. The experimental session began by asking the participant to close his eyes. Over the next $5 \mathrm{~min}$, the participants sat with their eyes closed to record resting brain activity. Each test began with the presentation of one pair of words, previously recorded, through headphones. When the subject was ready to state his sentence, he began to speak. The next pair of words was given 5-6 $s$ after the end of sentence articulation. Pairs of high- and low-related words were presented in pseudorandom order.

\section{EEG data acquisition and analysis}

EEG was recorded with an EEG device (Nicolet Viking EEG) according to the international 10-20 system from the following leads: Fp1, Fp2, F3, F4, F7, F8, Fz, T3, T4, T5, T6, C3, C4, Cz, P3, P4, Pz O1, O2, and Oz referred to linked earlobes. The sampling rate was $128 \mathrm{~Hz}$. Amplifiers had a bandpass from $0.5 \mathrm{~Hz}$ to $30 \mathrm{~Hz}$. For analysis, cerebral electrical activity was selected during the period from the beginning of word presentation to the start of the first oral articulation in each word pair. This period was defined in EEG with physiological markers (quick mouth movement). The sentences were recorded for posterior linguistic analysis.

We eliminated those EEG epochs with movement artifacts. Electromyography and EOG derivative from the movement of the chin, mouth, and eyes was indicated and marked. The final analyzed EEG period was $120 \mathrm{~s}$ in all participants. We used the fast Fourier transformation to estimate the power spectra. We analyzed the absolute power EEG rhythms in the following frequencies bands: delta $(1-3.5 \mathrm{~Hz})$, theta $(4-7.5 \mathrm{~Hz})$, alpha (8-12.5 Hz), beta $1(13-18.5 \mathrm{~Hz})$, beta $2(19-24.5)$, and beta $3(25-30 \mathrm{~Hz})$.

\section{Behavioral data analysis}

The analysis is based on the comparison of values between the group of healthy subjects and the group of patients with schizophrenia. The response variables were the latencies (time in seconds) and length of sentences (number of words) constructed using high and

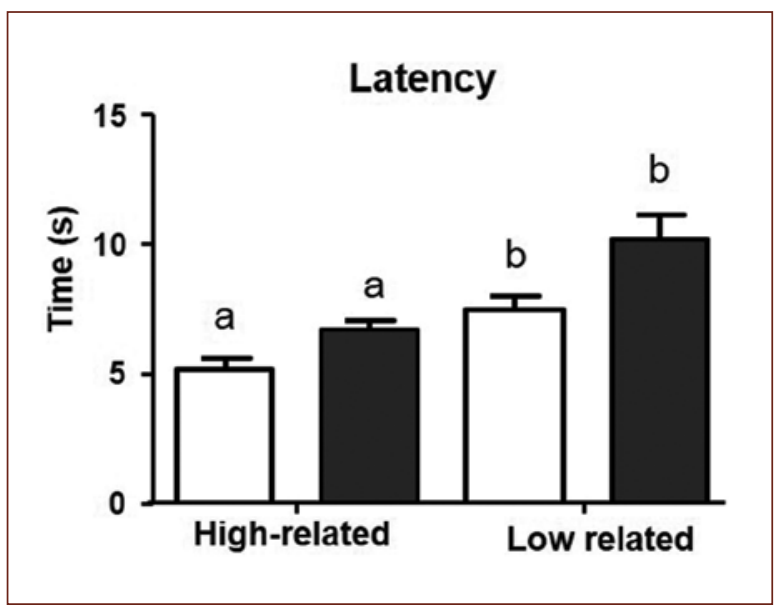

Figure 1. Comparison of latency to produce sentences between healthy (white) and schizophrenic (black) men with high and low relatedness word pairs. Data are means \pm standard deviation ( $n=15$ healthy and $n=11$ schizophrenic men). Letters indicate significant differences. Details of statistics are given in the text.

low relation word pairs. Due to the different number of subjects in each group, we used the Mann-Whitney $U$ test to compare the latency between groups and between the two stimulus conditions (high and low word pair relatedness). For statistical analysis and graphical representations, we used the program Prism 5 for Windows (GraphPad Software Inc., San Diego, USA, 2002).

\section{Results}

In healthy subjects, the latency for constructing sentences with high relatedness word pairs was $5.1 \mathrm{~S}( \pm 0.37 \mathrm{SD})$ and with low relatedness pairs was $7.4 \mathrm{~s}( \pm 0.52 \mathrm{SD})$. Subjects with schizophrenia constructed sentences using pair of high relatedness word pairs in $6.7 \mathrm{~s}( \pm 0.30 \mathrm{SD})$ and low relatedness pairs in $10.1 \mathrm{~s}( \pm 0.97 \mathrm{SD})$.

Kruskal-Wallis (KW) test showed significant differences in the latency to produce sentences ( $K W=47.75$, $p<0.0001$ ), post hoc Dunn's multiple comparison tests showed that this difference depended only on word pair relatedness (Fig. 1).

We counted the number of words utilized to construct sentences. Healthy subjects incorporated $5.86( \pm 0.91 \mathrm{SD})$ words in sentences with high relatedness word pairs and used 7.8 words $( \pm 0.91$ S.D) to form sentences with low relatedness pairs. Subjects with schizophrenia incorporated 7 ( \pm 1.0 S.D) words in 


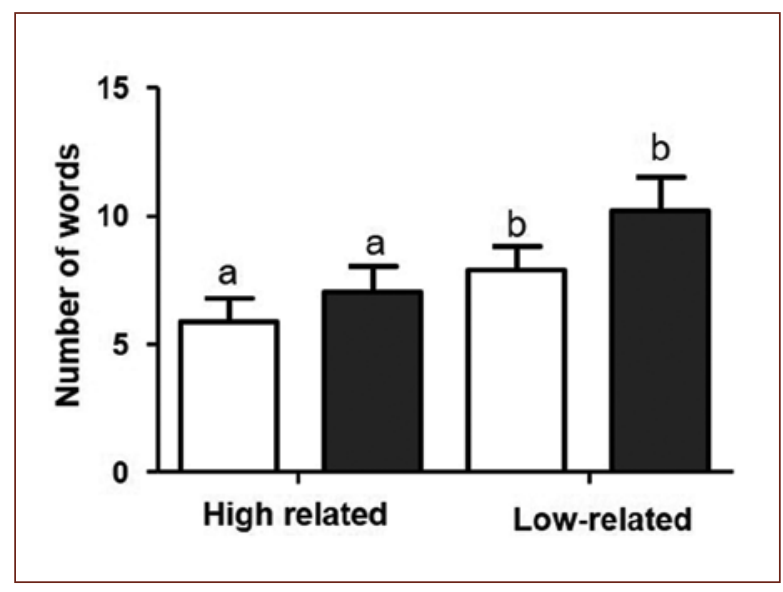

Figure 2. Difference in number of words used to produce sentences between healthy (white) and schizophrenic (black) men, with high and low relatedness word pairs. Data are means \pm standard deviation ( $n=15$ healthy and $\mathrm{n}=11$ schizophrenic men). Letters indicate significant differences. Details of statistics are given in the text.

sentences with high relatedness pairs and 10.18 words $( \pm 1.3 \mathrm{SD})$ in sentences with low relatedness pairs.

$\mathrm{KW}$ test showed significant differences in the number of words to construct sentences ( $K W=35.92, p<0.0001)$, post hoc Dunn's multiple comparison tests showed that this difference depended only on word pair relatedness (Fig. 2).

\section{EEG data}

EEG data were compared between groups using the Mann-Whitney U-test to assess the statistical significance of the difference in the absolute power of each EEG band. During the construction of sentences with high relatedness word pairs, healthy subjects showed significant higher absolute power in delta and alpha rhythm than schizophrenic patients. However, schizophrenic patients showed significantly higher absolute power in theta, beta 1, beta 2 , and beta 3 rhythms compare to healthy subjects (Fig. 3).

During the construction of sentences with low relatedness word pairs, schizophrenic patients showed significant higher absolute power in delta, theta, and beta rhythms, while healthy subjects exhibited significantly higher alpha rhythm (Fig. 4).

\section{Topographical analysis}

Construction of sentences with highly related word pairs induced a different distribution of absolute power between the control and schizophrenic groups. The absolute power of alpha rhythm was increase in healthy subjects over the occipital leads. The absolute power of theta and beta rhythms is increase over the frontal and central leads in schizophrenic patients (Fig. 5).

Construction of sentences with low relatedness word pairs also induced different distribution of absolute power between the groups. In healthy subjects, we found enhancement of alpha rhythm, especially in occipital regions, as well as theta power in frontal areas. Schizophrenic patients showed an increase in absolute power in theta band in frontotemporal areas. In addition, a diffuse increase of absolute power in beta band appeared in schizophrenic patients (Fig. 6).

\section{Discussion}

There is extensive literature about deficits in verbal functioning in schizophrenia, showing various abnormalities in verbal production, comprehension, and cerebral lateralization of language ${ }^{19}$. Several functional magnetic resonance imaging studies using language paradigms also show abnormal processing in verbal fluency tasks and loss of left hemisphere lateralization in the temporal and frontal lobes of patients with chronic schizophrenia ${ }^{20}$.

Some authors Ford and Mathalon ${ }^{21}$ have argued that EEG measures of coherence indicate interdependence of activity in the frontal speech production and temporal speech reception areas during speech in control subjects, but not in schizophrenia patients. These data suggest that a corollary discharge from frontal areas fails to alert the auditory cortex that they are self-generated, leading to the misattribution of inner speech to external sources.

Wynn et al. ${ }^{22}$ found no differences between schizophrenic patients and controls in the ability to form global objects from local elements, during visual integration tests. This is relevant to our tests because we asked patients and control subjects to form coherent sentences (global object) from isolated words (local elements). The cognitive effort required for that kind of tasks involves information sorting (word pairs), to generate a coherent order. Schizophrenic patients have difficulty maintaining thematic consistency. In our study, patients formed sentences with no morphological deficits, but which were thematically incoherent. To construct a sentence, using pairs of word, it is necessary to maintain the words in the short-term memory while seeking a context in which to put them, as well as constant monitoring to avoid mistakes ${ }^{23}$. Short-term memory and 


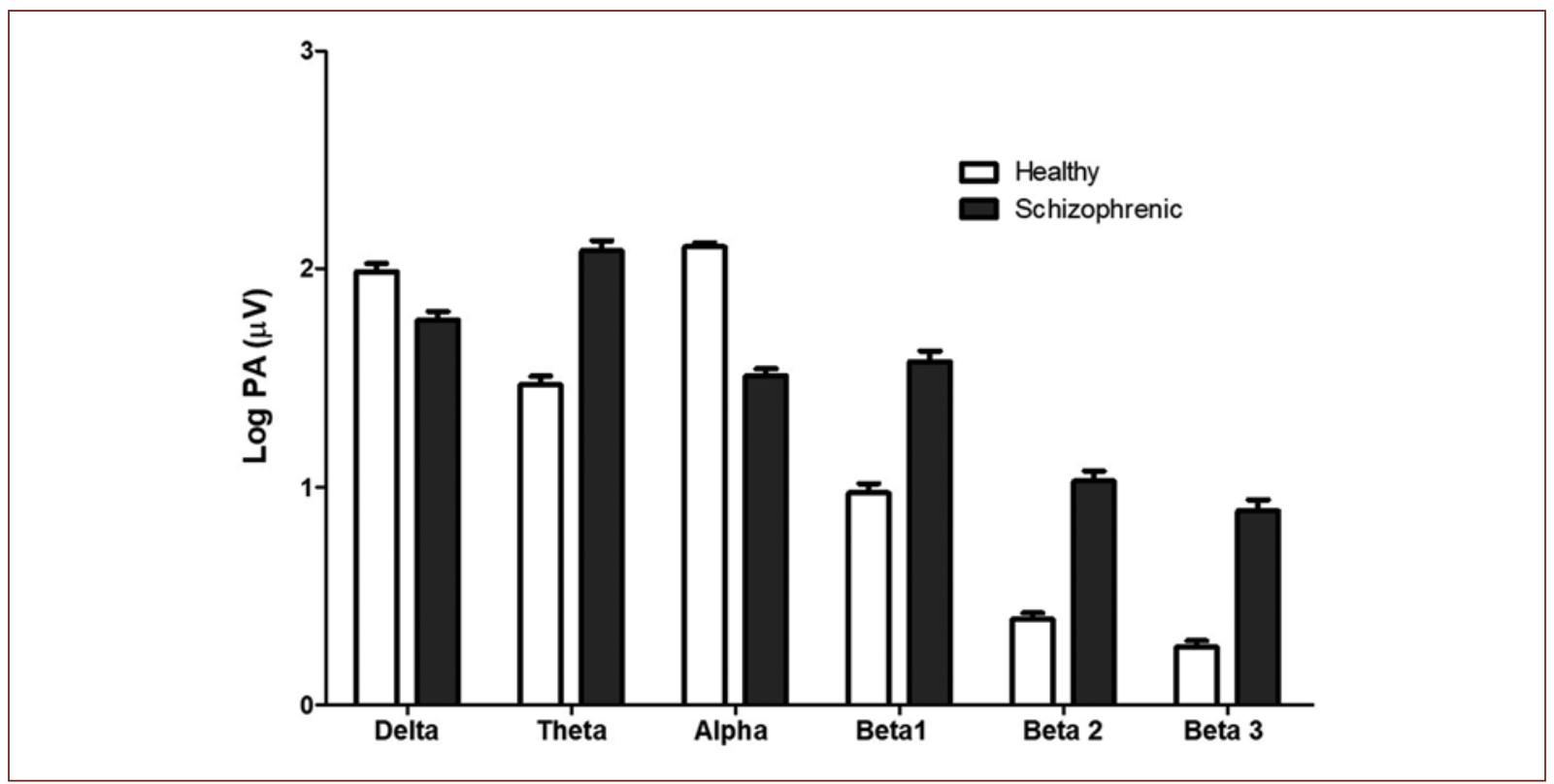

Figure 3. Comparison of the absolute power (Log PA) obtained during sentence production using highly related word pairs. Details of statistics are given in the text.

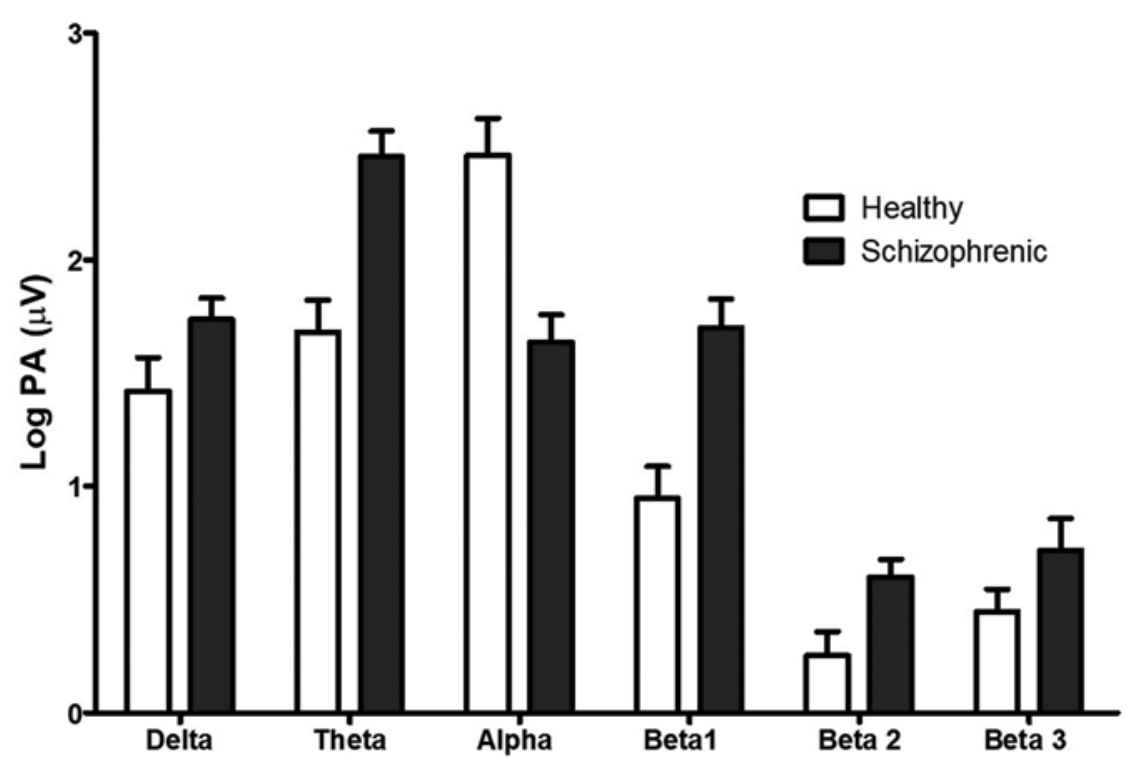

Figure 4. Comparison of the absolute power (Log PA) obtained during sentence production using low relatedness word pairs.

monitoring are functions associated with the work of the frontotemporal and frontoparietal cortex ${ }^{24-26}$.

Expression of language is a complex process and involves a distributed network in cortical regions. Our results demonstrate that when control subjects form sentences with highly related word pairs, absolute power over theta and beta bands is more expressive on frontopolar and frontal-inferior regions, respectively. Lin et al. ${ }^{27}$ suggested that theta power increases during longer latencies; furthermore, alpha-band oscillations are suggested 


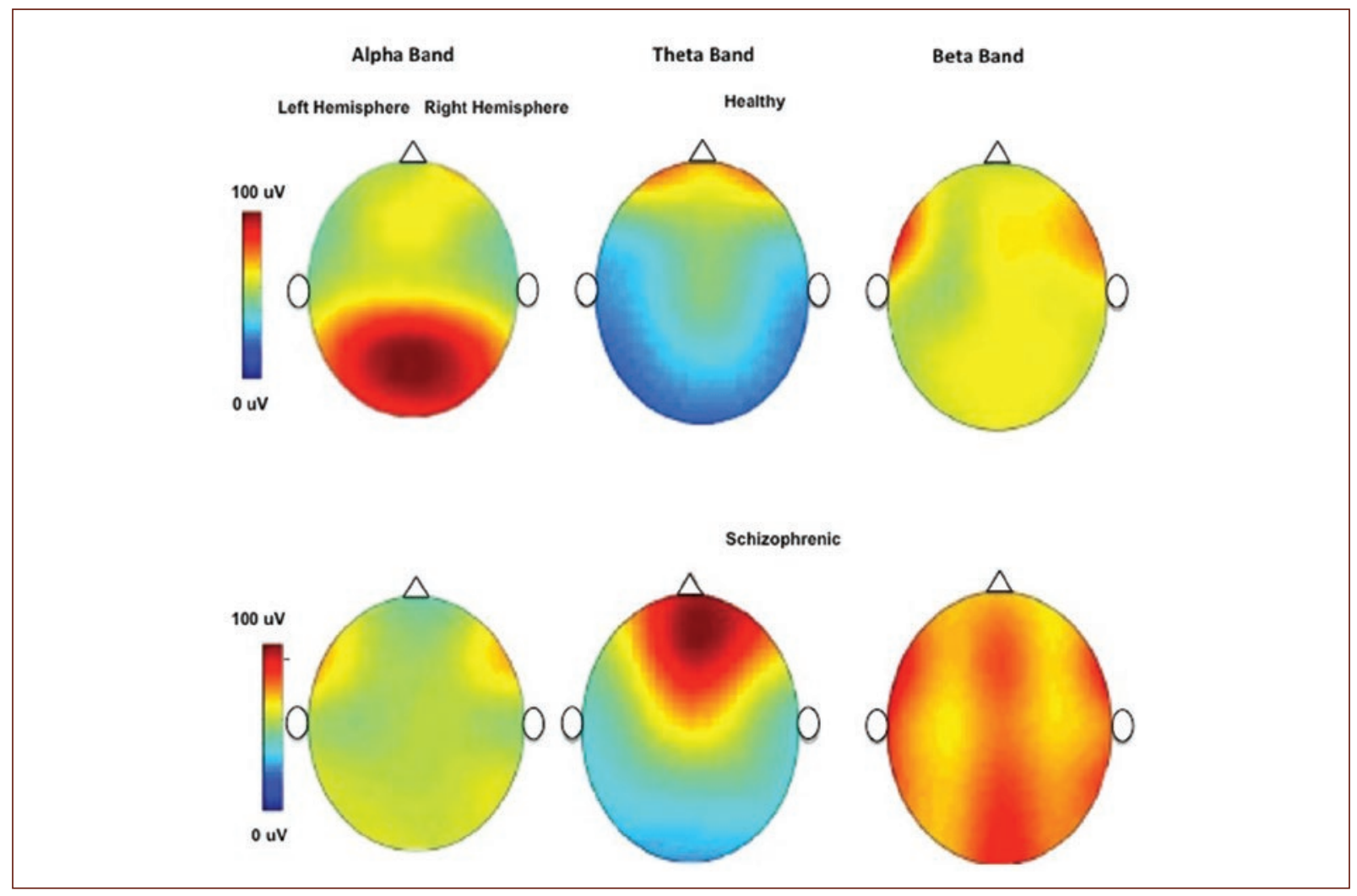

Figure 5. Brain mapping while producing sentences with high relatedness word pairs.

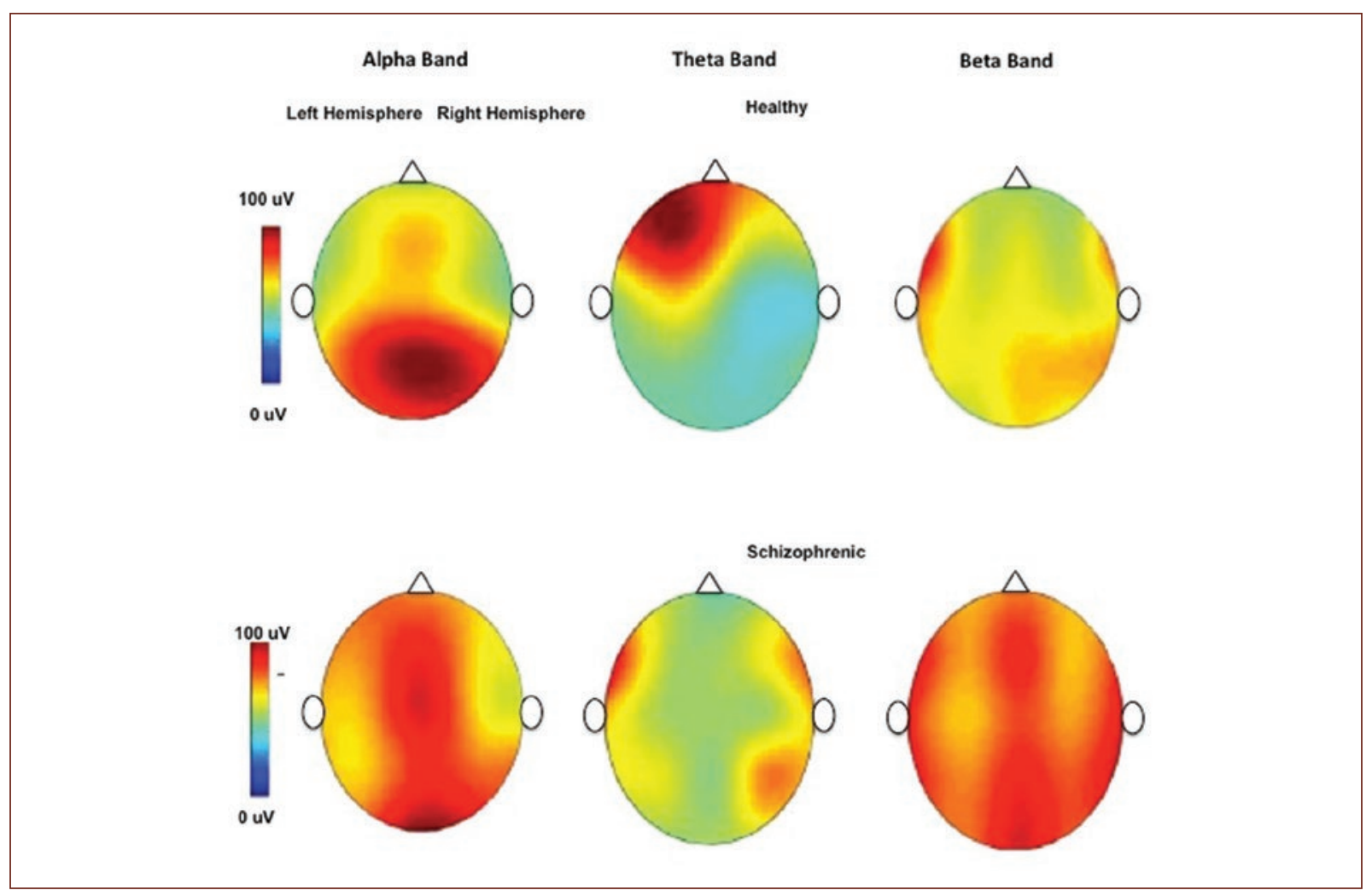

Figure 6. Brain mapping while producing sentences with low relatedness word pairs. 
to be closely associated with attentional selection, specifically anticipatory and temporal attention ${ }^{28}$.

In schizophrenic patients, the absolute power of the theta band increased in the frontotemporal regions in both hemispheres with an extension to the right parietal region. The beta band also increased diffusely. Doesburg et al. suggested that oscillatory synchronization and cross-frequency interactions are mechanisms of functional integration among distributed brain areas that support expressive language processing ${ }^{29}$.

Theta activity has been found over frontal regions when subjects form images during mental task performance ${ }^{30}$. We believe that a sentence forming task involves organizing images, but in more complex tasks, the images may be less structured. On the other hand, beta activity is associated with sensory information analysis and decision-making because the task implies a goal-oriented behavior. The assumption behind this idea is that the motor system initiates active movement preparation on the reception of stimulus input ${ }^{31}$. Language production in schizophrenia is disordered and filled with irrelevant pieces of information and derailments. Such erratic discourse may be linked to the inability to use pragmatic rules, attention, action planning, ordering, and sequencing ${ }^{32}$.

Finally, we consider that sentence production using high and low relatedness word pairs could be used to explore different cognitive process, such attention, WM, executive functions, as well as the search for coherence. We believe that in the area of neuropsychological rehabilitation, particularly for schizophrenic patients, it is necessary to create methods to solve problems in discourse construction, looking into different cognitive processes that are required for generating meaning in patients' speech.

\section{Conclusion}

There are significant differences in behavior and EEG activity during sentences production, using low and high relatedness words. Specifically, absolute power is increased in patients with schizophrenia over the theta, and beta rythms. We consider that producing sentences with high or low relatedness words could be used for new experimental paradigms.

Differences in EEG patterns in schizophrenic patients compared to healthy men.

\section{Funding}

CONACYT 93034 to HJPG.

\section{Conflicts of interest}

The authors declare that they have no conflicts of interest.

\section{Ethical disclosures}

Protection of human and animal subjects. The authors declare that the procedures followed were in accordance with the regulations of the relevant clinical research ethics committee and with those of the Code of Ethics of the World Medical Association (Declaration of Helsinki).

Confidentiality of data. The authors declare that they have followed the protocols of their work center on the publication of patient data.

Right to privacy and informed consent. The authors have obtained the written informed consent of the patients or subjects mentioned in the article. The corresponding author is in possession of this document.

\section{References}

1. Bleuler E. Dementia Praecox or the Group of Schizophrenias. Oxford: International Universities; 1950.

2. Andreasen NC. Thought, language, and communication disorders I. Clinical assessment, definition of terms, and evaluation of their reliability. Arch Gen Psychiatry. 1979;36:1315-21.

3. Gattaz WF, Mayer S, Ziegler P, Platz M, Gasser T. Hypofrontality on topographic EEG in schizophrenia. Correlations with neuropsychological and psychopathological parameters. Eur Arch Psychiatry Clin Neurosci. 1992;241:328-32.

4. American Psychiatric Association. Diagnostic and Statistical Manual of Mental Disorders (DSM-V). $5^{\text {th }}$ ed. Washington: American Psychiatric Association; 2015.

5. Manschreck TC, Maher BA. Semantic priming in thought disorders and schizophrenic patients. Schizophr Res. 1988;1 61-6.

6. Neely JH. Semantic priming effects in visual word recognition: a selective review of current findings and theories. In: Besner D, Humphreys GW, editors. Basic Processes in Reading and Visual Word Recognition. New York: Routledge; 2012.

7. Pulvermüller F. The Neuroscience of Language: on Brain Circuits of Words and Serial Order. Cambridge: Cambridge University Press; 2003.

8. Picton TW. The P300 wave of the human event-related potential. J Clin Neurophysiol. 1992:9:456-79.

9. Johnson R Jr. On the neural generators of the $\mathrm{P} 300$ component of the event-related potential. Psychophysiology. 1993;30:90-7.

10. Rugg M, Coles MG. Electrophysiology of Mind: event Related Brain Potentials and Cognition. Oxford: Oxford University Press; 1995.

11. Hughes JR, John ER. Conventional and quantitative electroencephalography in psychiatry. J Neuropsychiatry Clin Neurosci. 1999;11: 190-208.

12. van der Stelt $O$, Belger A. Application of electroencephalography to the study of cognitive and brain functions in schizophrenia. Schizophr Bull. 2007:33:955-70.

13. Harmony T, Fernández T, Silva J, Bernal J, Díaz-Comas L, Reyes A, et al. EEG delta activity: an indicator of attention to internal processing during performance of mental tasks. Int J Psychophysiol. 1996;24: 161-71.

14. Petrantonakis $P$, Hadjileontiadis $L$. Adaptive emotional information retrieval from EEG signals in the time-frequency domain. IEEE Trans Signal Process. 2012;60:132-48.

15. Lehmann D, Faber PL, Galderisi S, Herrmann WM, Kinoshita T, Koukkou M, et al. EEG microstate duration and syntax in acute, medication-naive, first-episode schizophrenia: a multi-center study. Psychiatry Res. 2005;138:141-56.

16. Annett M. A classification of hand preference by association analysis. $\mathrm{Br}$ J Psychol. 1970;61:303-21. 
Rev Mex Neuroci. 2020;21(2)

17. Andreasen NC. Scale for the Assessment of Positive Symptoms (SAPS). lowa: University of lowa; 1984.

18. González HP, Ramos DG, Romero VA. Características de la evocación lexical libre en una población mexicana adulta. Neuropsicología Latinoam. 2012;4:42-6

19. DeLisi LE. Speech disorder in schizophrenia: review of the literature and exploration of its relation to the uniquely human capacity for language. Schizophr Bull. 2001;27:481-96.

20. Sommer IE, Ramsey NF, Kahn RS. Language lateralization in schizophrenia, an fMRI study. Schizophr Res. 2001;52:57-67.

21. Ford JM, Mathalon DH. Electrophysiological evidence of corollary discharge dysfunction in schizophrenia during talking and thinking. J Psychiatr Res. 2004;38:37-46.

22. Wynn JK, Roach BJ, Lee J, Horan WP, Ford JM, Jimenez AM, et al. EEG findings of reduced neural synchronization during visual integration in schizophrenia. PLoS One. 2015;10:e0119849.

23. Levelt WJ. Lexical Access in Speech Production. Netherlands: Springer 2001.

24. Sauseng $P$, Klimesch W, Schabus M, Doppelmayr M. Fronto-parietal EEG coherence in theta and upper alpha reflect central executive functions of working memory. Int J Psychophysiol. 2005;57:97-103.
25. Wolf DH, Gur RC, Valdez JN, Loughead J, Elliott MA, Gur RE, et al. Alterations of fronto-temporal connectivity during word encoding in schizophrenia. Psychiatry Res. 2007;154:221-32.

26. van den Heuvel MP, Mandl RC, Stam CJ, Kahn RS, Pol HE. Aberrant frontal and temporal complex network structure in schizophrenia: a graph theoretical analysis. J Neurosci. 2010;30:15915-26.

27. Lin $C L$, Jung $M, W u$ YC, She HC, Jung TP. Neural correlates of mathematical problem solving. Int J Neural Syst. 2015;25:1550004.

28. Klimesch W. $\alpha$-band oscillations, attention, and controlled access to stored information. Trends Cogn Sci. 2012;16:606-17.

29. Doesburg SM, Vinette SA, Cheung MJ, Pang EW. Theta-modulated gamma-band synchronization among activated regions during a verb generation task. Front Psychol. 2012;3:195.

30. Inanaga K. Frontal midline theta rhythm and mental activity. Psychiatry Clin Neurosci. 1998:52:555-66.

31. Zhang Y, Chen Y, Bressler SL, Ding M. Response preparation and inhibition: the role of the cortical sensorimotor beta rhythm. Neuroscience. 2008;156:238-46.

32. Marini A, Spoletini I, Rubino IA, Ciuffa M, Bria P, Martinotti G, et al. The language of schizophrenia: an analysis of micro and macrolinguistic abilities and their neuropsychological correlates. Schizophr Res. 2008;105:144-55. 